\title{
MODELAGEM E SIMULAÇÃO DO PROCESSO DE PRODUÇÃO DE FANTASIA: UM ESTUDO DE CASO NA ESCOLA DE SAMBA ACADÊMICOS DO GRANDE RIO
}

\author{
Allan Cormack \\ Universidade Federal Fluminense \\ allan.cormack@gmail.com \\ Camila Soares \\ Universidade Federal Fluminense \\ camilavidaurresoares@gmail.com \\ Daniele Affonso \\ Universidade Federal Fluminense \\ danieledantas@yahoo.com.br \\ Edwin Mitacc Meza \\ Universidade Federal Fluminense \\ emitacc@vm.uff.br \\ Erenildo Motta \\ Universidade Federal Fluminense \\ erenildo_motta@hotmail.com \\ Fernanda Bainha \\ Universidade Federal Fluminense \\ fernandabainha@yahoo.com.br \\ Iara Tammela \\ Universidade Federal Fluminense \\ iaratammela@vm.uff.br
}

\begin{abstract}
Resumo
O Carnaval enfrenta problemas em sua forma de organização e produção que ameaçam a estrutura das escolas. O empirismo nos processos de produção é uma característica das escolas de samba e traduz sua evolução ao longo dos anos. Além da ausência de renda fixa e padronização dos processos produtivos, o fator tempo também é um dos pontos críticos da produção.

O presente artigo foca em pesquisar o processo produtivo de fabricação de fantasias com intuito de contribuir com soluções para seu aperfeiçoamento. Foram analisadas as etapas de fabricação de cinco diferentes modelos de fantasias de ala e identificados os gargalos de produção.

O software FlexSim de modelagem e simulação auxiliou na criação de novos cenários de produção, tornando-se possível propor melhorias para otimizar este processo produtivo.

Palavras-Chaves: Carnaval; Produção de fantasia; Processo Produtivo; Modelagem e Simulação; FlexSim.
\end{abstract}

\footnotetext{
Abstract

Carnival faces problems in its form of organization and production that threaten the structure of the samba school. The empiricism in the production processes of carnival is a
} 
characteristic in these samba clubs, reflecting its creation and evolution through the years. Shortened time associated with a lack of fixed income and lack of standardization of the production processes brings wastage and complicates control and development of the planned activities.

This article analyzes the production process of five different models of costumes created for a carnival parade identifying bottlenecks and proposing improvements in the production process through the method of modeling and simulation with support of Flexsim software.

Keywords:

Carnival; Costumes Production; Production Process; Modeling and Simulation; FlexSim.

\section{INTRODUÇÃO}

O Carnaval enfrenta um problema crônico que hoje ameaça a estrutura das escolas de samba: a falta de recursos financeiros (renda fixa) e a ausência de padronização nos seus processos de produção. O empirismo nos processos de produção dos desfiles carnavalescos é o que traduz a criação e evolução das escolas de samba ao longo dos últimos 83 anos de sua existência.

Com a criação do Sambódromo em 1984 (LIESA, 2014), os desfiles cresceram em volume e efeitos especiais tornando a festa mais competitiva e consequentemente, mais dispendiosa. Com essa nova realidade surge a necessidade das escolas se organizarem para conseguirem manter-se no grupo especial frente aos diversos desafios financeiros e estruturais. Neste cenário, o Grêmio Recreativo Escola de Samba (G.R.E.S.) Acadêmicos do Grande Rio, criado em 1988, oriundo de um bloco carnavalesco localizado no bairro Prainha, no município de Duque de Caxias, também enfrenta desafios ligados à falta de gestão nos seus processos produtivos.

Esta agremiação é a mais nova escola de samba do grupo especial e, assim como as demais escolas, é uma organização não governamental. Ao longo dos últimos 10 anos, a Grande Rio foi classificada entre as seis melhores escolas, porém nunca obteve o primeiro lugar e, por isso, luta todos os anos para conquistar este título.

Nesse sentido, dependendo do período do ano em que o grêmio recreativo faz a captação de recursos, o tempo de produção do seu desfile pode ser alongado ou encurtado, o que acarreta em gastos expressivos, que muitas vezes, não estão disponíveis e faz com que a escola de samba contraia dívidas de um ano para o outro. Portanto, o fator tempo somado à falta de renda fixa e a não existência de padronização de processos de fabricação de fantasia, provocam desperdícios e dificultam o controle e desenvolvimento das atividades planejadas do processo produtivo das agremiações carnavalescas.

Segundo as estimativas da Secretaria de Desenvolvimento Econômico, Energia, Indústria e Serviços, o Carnaval movimentou cerca de $\mathrm{R} \$ 1,6$ bilhões de reais, trazendo um quantitativo de aproximadamente 971 mil turistas à cidade do Rio de Janeiro em 2014. Nesse contexto, este estudo é de suma importância, já que acredita-se que a análise do sistema de produção do carnaval aliada às boas práticas de gestão podem garantir que a escola objeto deste estudo cumpra seu objetivo de aperfeiçoar sua técnicas de gestão, reduzindo custos e tempo de produção.

O presente artigo foca em pesquisar o processo produtivo de fabricação de fantasias com objetivo de contribuir com soluções para seu aperfeiçoamento.

Foram analisadas as etapas de fabricação de cinco diferentes modelos de fantasias de ala e identificados os gargalos de produção. O software FlexSim de modelagem e simulação auxiliou na criação de novos cenários de produção, tornando-se possível propor melhorias.

\section{METODOLOGIA}

Segundo Gil (2002), a pesquisa é o procedimento racional e sistemático com o 
objetivo de proporcionar respostas aos problemas propostos. O presente trabalho é classificado como pesquisa exploratória, de acordo com os métodos de pesquisa citados e com base em seus objetivos (Vergara, 2011). Neste tipo de pesquisa, uma das principais características é a análise de exemplos que estimulem a compreensão sobre o objeto de estudo, além de não se ter verificado uma variedade de estudos que abordem otimizações nos processos de produção do Carnaval.

Com base nos procedimentos técnicos utilizados, esta pesquisa classifica-se como estudo de caso, pois possui caráter de profundidade e detalhamento sobre o processo de produção da agremiação objeto deste estudo, investigando o fenômeno contemporâneo dentro de seu contexto real. (GIL, 2002). Para que o Estudo de caso possibilite o amplo e detalhado conhecimento sobre o processo produtivo descrito neste trabalho e então contribua com solução para seu aperfeiçoamento, utilizou-se a metodologia de Simulação.

\subsection{METODOLOGIA DE SIMULAÇÃO}

Simulação, de acordo com Ingalls (2008), é o processo de design do modelo de um sistema real e de condução de experimentos com este modelo com o própósito de entender o comportamento do sistema ou de avaliar várias estratégias (dentro dos limites impostos por um critério ou por um conjunto de critérios) para a operação do sistema. Lima et al. (2011) acrescenta que a simulação computacional permite criar modelos de um sistema real, onde se podem fazer alterações a fim de realizar estudos, mas sem necessidade de alterar o sistema na prática.

Desta forma, para que a simulação seja encarada como uma metodologia experimental e aplicada, faz-se necessário o uso de uma abordagem sistêmica, pois se busca analisar o desempenho total do sistema e não apenas de suas partes. Esta é uma técnica de planejamento muito difundida, principalmente nos EUA, Japão e Europa. No Brasil, esta técnica vem sendo utilizada desde 1970, pelas grandes empresas. (LIMA et al, 2011)

Segundo Lima et al., 2011, um trabalho de simulação pode ser desenvolvido de acordo com as etapas apresentadas na Figura 1.

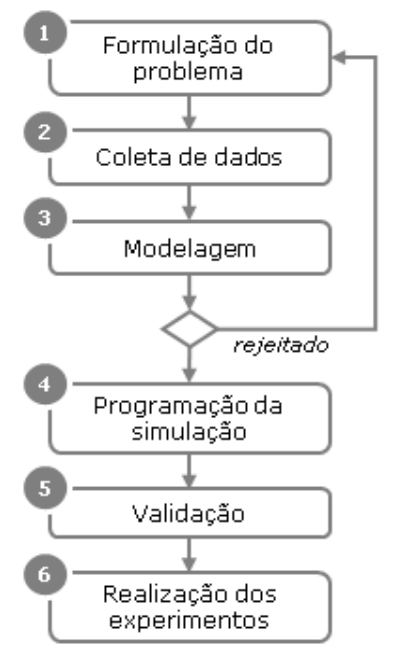

Figura 1. Fluxograma do processo de simulação

Fonte: Adaptado de Lima et al.(2011)

Fase 1: Formulação do problema: Na etapa de formulação, os objetivos da simulação devem ser claramente definidos, a fim de delimitar a amplitude e a profundidade das análises e os recursos disponíveis.

Fase 2: Coleta de dados: Segundo o autor, o modelo de simulação será tão confiável quanto os dados de entrada também o forem. Após a coleta dos dados, estes devem ser tratados para identificar as possíveis falhas nos valores mostrados e aumentar o conhecimento a cerca do fenômeno. 
Fase 3: Modelagem: A modelagem deve ter foco na maximização da capacidade do modelo em aumentar o conhecimento que se tenha do sistema a que se refere. A técnica de modelagem a ser utilizada neste trabalho será o IDEF-SIM (Integrated Definition methodsSimulation) proposto por Leal et al. (2008), que será detalhada adiante.

Fase 4: Programação da simulação: A etapa de programação da simulação é desenvolvida através de uma programação computacional e uma fase de implementação.

Para a execução desta etapa, o presente trabalho utilizou o software FlexSim que é, segundo Zhu et al. (2014), um conjunto de tecnologia de computador 3-D de processamento de imagem, técnicas de simulação, tecnologia de inteligência artificial e técnicas de manipulação de dados. Para este autor, o FlexSim é adequado para produção, armazenamento, entrega, sistema de transporte e outros campos, no qual o software fornece dados originais, modelagem de entrada, modelo de operação para realizar experimentos de simulação e otimiza o sistema.

Fase 5: Validação: A validação do modelo computacional assegura que a implementação e a programação computacional do modelo estão corretas, e requer que as variáveis de saída do modelo sejam identificadas e que seja especificada sua precisão com relação ao sistema real.

Fase 6: Realização de experimentos: Para esta fase, é necessário estabelecer critérios de como os experimentos devem ser conduzidos, a fim de que os resultados obtidos para análise não gerem deduções errôneas por parte do modelador e usuário.

\section{DESCRIÇÃO E DEFINIÇÃO DO PROBLEMA}

Este estudo contempla a análise do processo de fabricação de fantasia da escola de samba Acadêmicos da Grande Rio do ano de 2013, com objetivo de analisar as etapas de produção de cinco modelos diferentes de fantasias de ala, identificar gargalos de produção e propor melhorias nesse processo produtivo. Dados sobre os cinco modelos de fantasia, apresentados na Figura 2, foram fornecidos por especialistas da agremiação para serem analisados no presente estudo e técnicas de modelagem e simulação computacional foram utilizadas para testar as propostas de melhoria.
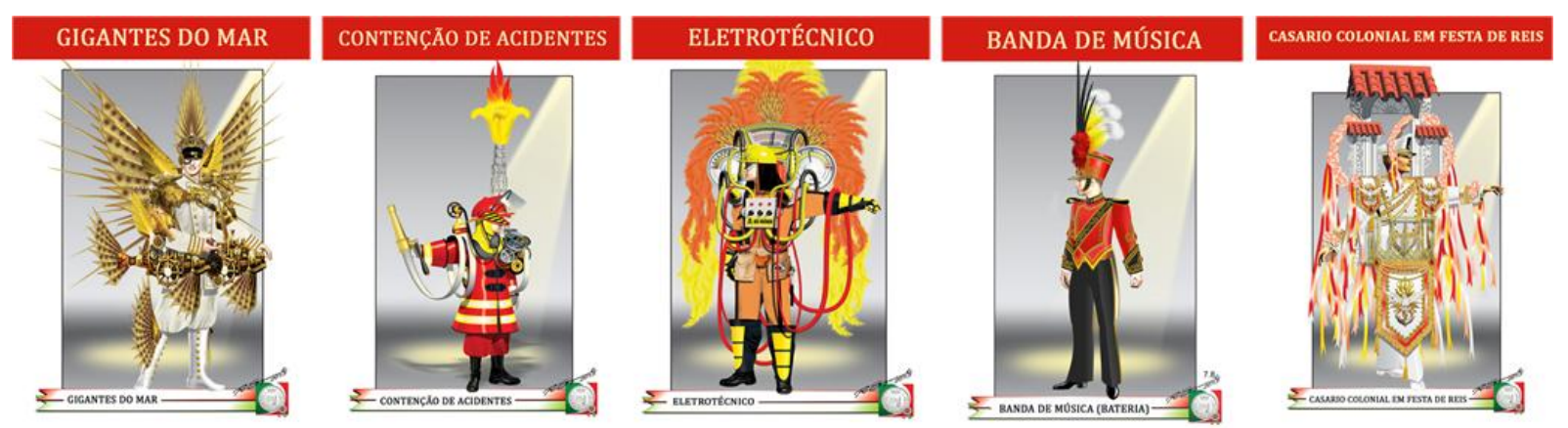

Figura 2. Modelos de fantasias utilizados

Fonte: G.R.E.S. Acadêmicos do Grande Rio (2013)

A partir das observações do relatório da escola, foram identificados quatro setores produtivos: Pré-produção; Corte e Pintura; Montagem e Acabamento e Embalagem. Dentro destes, nove etapas no processo produtivo são desenvolvidas: Modelagem, Produção de placas, Produção de estrutura de arame, Enfesto e Corte, Pintura de artes/placas, Pintura de artes/tecidos, Costura, Montagem/Adereço e Embalagem.

Para facilitar o entendimento das etapas de produção, a figura 3 apresenta o fluxograma abaixo com o mapeamento dos processos de fabricação de fantasia de ala: 


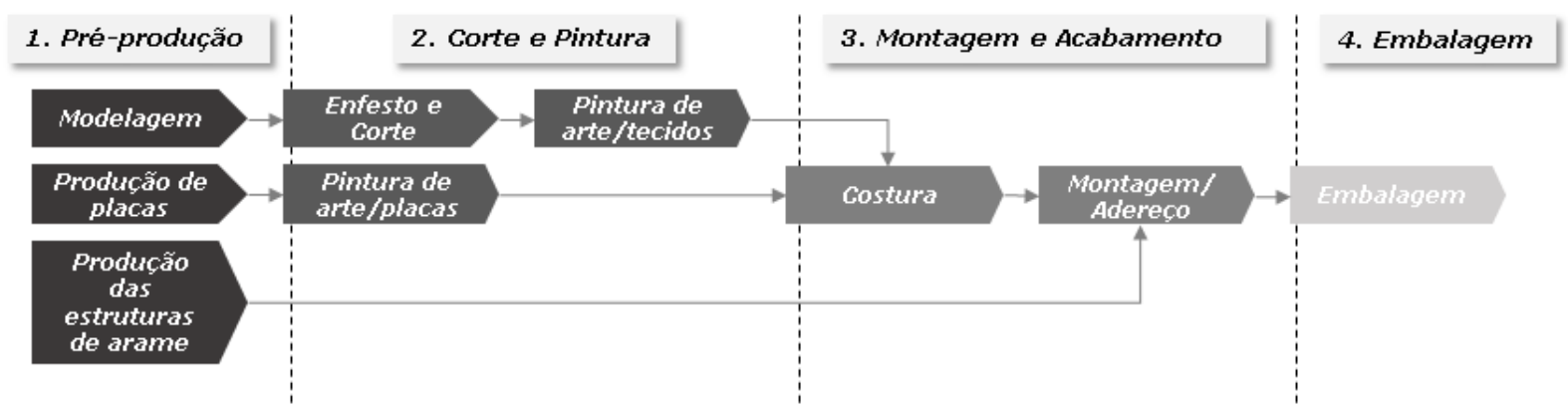

Figura 3. Processos de fabricação de fantasias de ala

Fonte: Autoria própria

1. Setor de Pré-produção: Setor responsável pela definição das ordens de produção. Esta ordem de produção contempla o material a ser utilizado para a produção da fantasia e o quantitativo a ser produzido.

Modelagem: Processo que contempla a criação dos moldes de cada peça de fantasia manualmente em papel pardo. Este molde é usado como base para os cortes dos tecidos posteriormente.

Produção das placas: Trata-se de placas com moldes em acetato ou borracha EVA (Etil Vinil Acetato), que são usados para criar figuras características de cada fantasia. Como por exemplo, a fantasia Gigante do Mar ilustrada na Figura 4, que possui um adereço de mão, feito em acetato.

Para a produção dessas placas, esculturas em gesso são utilizadas como moldes (gabarito), que auxiliam no processo de transformação das placas na máquina termoformadora (VacuumForming).

Produção das estruturas de arame: Processo no qual são projetadas e concebidas as estruturas de arame que podem ou não, compor a fantasia (estrutura de cabeça, estrutura de ombro, dentre outros). A parte de tecido da fantasia utiliza essa estrutura de arame para ser montada, caso seja necessário (costura, colagens, etc.).

No exemplo da Figura 4, a fantasia Gigante do Mar evidencia a estrutura de arame que fora utilizada na parte dos ombros.

2. Setor de Corte e Pintura: Este setor responde pelo enfesto do tecido (atividade de sobrepor os tecidos para corte) e corte dos tecidos conforme gabarito. Adicionalmente, neste setor é realizada a pintura de arte nos tecidos e placas.

Enfesto $\boldsymbol{e}$ corte: neste processo os tecidos são dobrados e os moldes são montados sobre o mesmo para serem cortados em escala. Posteriormente, estes tecidos são insumos para a célula de montagem e acabamento.

Pintura de arte/placas: neste processo as placas são pintadas após saírem da máquina termoformadora, como pode ser visto no adereço de mão da fantasia Gigantes do Mar mostrada na Figura 4. A placa foi feita em acetato dourado e depois recebeu um tratamento de envelhecimento em pintura de arte.

Pintura de arte/tecidos: Consiste em pintar os tecidos que irão compor a fantasia. Estes tecidos são pintados quando saem do setor de costura ou do setor de corte. Como por exemplo, as asas da fantasia Gigantes do Mar, apresentada na Figura 4, que sofreram um envelhecimento no tecido dourado. Neste caso, o tecido saiu do corte e foi para a pintura.

3. Setor de Montagem e Acabamento: Refere-se à montagem da fantasia agrupando todos os elementos produzidos nos setores.

Costura: Consiste em costurar peças de tecido que saem do setor de Enfesto e Corte, tendo como produto final as bases das fantasias. Esta base recebe a pintura de arte e a montagem dos adereços.

Montagem/Adereço: Consiste em agrupar os insumos recebidos dos processos anteriores. Os insumos chegam para a equipe de Montagem e eles realizam a colocação de 
adereços e acessórios (pedraria, penas e plumas, dentre outros) para finalizar a produção da fantasia.

4. Setor de Embalagem: Consiste em embalar as fantasias prontas enviadas pelo setor de Montagem e Acabamento. O processo de embalagem consiste em separar as fantasias por tamanho ( $\mathrm{P}, \mathrm{M}$ ou $\mathrm{G})$, embalar com cobertura de plástico e agrupar os componentes da fantasia (estrutura de arame adereçada, vestuários, sapato, adereços de mão e sapatos).

\section{GIGANTES DO MAR}

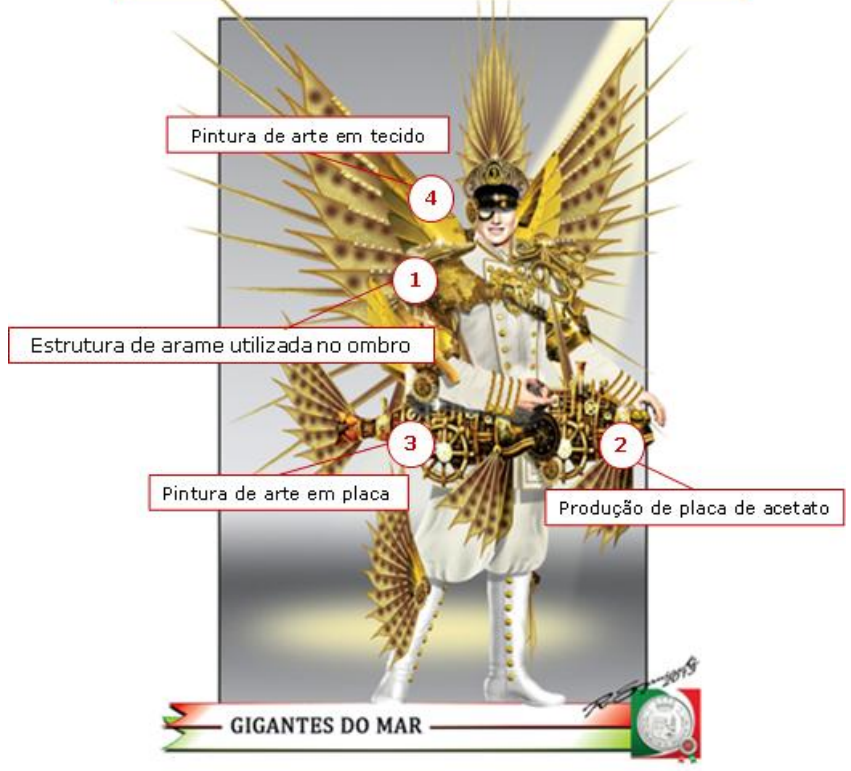

Figura 4. Modelo da fantasia "Gigantes do Mar"

Fonte: G.R.E.S. Acadêmicos do Grande Rio (2013)

Após observação e levantamento de dados, identificou-se que o setor de Montagem e Acabamento é o que consome maior tempo de produção (hora-homem) no tempo total do processo, sendo então, o gargalo da produção de fantasias. Estes dados serão apresentados e analisados a seguir.

\section{COLETA DE DADOS}

Segundo Moreira (2001), a coleta de dados é um processo de recolhimento dos fatos e informações disponíveis que serão processados quando houver necessidade. De acordo com Chwif e Medina (2007), um cuidado especial deve ser tomado para diferenciar o que são dados de entrada (valores fornecidos ao modelo de simulação) e o que são dados de saída (valores obtidos do modelo de simulação).

No presente estudo, a coleta para obtenção dos dados de entrada foi baseada na análise do Relatório de Produção de Fantasias do ano de 2013 e na observação do atual processo produtivo. O relatório forneceu informações inerentes à quantidade e tipo de material para produção, custo por modelo e imagens das fantasias.

A observação foi realizada por pesquisador especialista do setor e através dela foi possível determinar: quantidade de hora-homem necessária a cada etapa da produção dos cinco modelos de fantasias e os recursos humanos necessários a estas etapas. De acordo com Chwif e Medina (2007), no momento de observação, deve-se certificar da importância que a qualidade dos dados observados tem em todo modelo. Ainda segundo o autor, é necessário discussões do problema com os especialistas do setor para que ocorra a definição do escopo, possibilitando a modelagem conceitual que servirá para futura simulação computacional. 
Para entendimento dos processos produtivos foram coletados dados referentes ao tempo de produção por setor, em cada etapa, na confecção das fantasias através de observação direta nos ateliês de produção. A síntese dessas informações encontra-se na Tabela 1, apresentada abaixo.

Tabela 1. HH demandada por etapa de fabricação para cada modelo de fantasia

\begin{tabular}{|c|c|c|c|c|c|c|c|}
\hline \multirow{2}{*}{ Setores e processos } & \multirow{2}{*}{$\begin{array}{l}\text { Recusos } \\
\text { humanos }\end{array}$} & \multicolumn{5}{|c|}{ HH demandada por Fantasia } & \multirow{2}{*}{$\begin{array}{c}\text { HH } \\
\text { médio }\end{array}$} \\
\hline & & $F 1$ & $F 2$ & $F 3$ & $F 4$ & Fs & \\
\hline 1.Pré-produção & 6 & 134 & 166 & 142 & 102 & 182 & 145,2 \\
\hline 1.1 Modelagem & 3 & 16 & 16 & 16 & 16 & 16 & 16,00 \\
\hline 1.2 Produção de placas & 2 & 48 & 80 & 56 & 16 & 96 & 59,20 \\
\hline 1.3 Produção de estruturas de arame & 1 & 70 & 70 & 70 & 70 & 70 & 70,00 \\
\hline 2. Corte e Pintura & 11 & 88 & 72 & 64 & 56 & 72 & 70,4 \\
\hline 2.1 Enfesto e Corte & 6 & 56 & 56 & 56 & 56 & 56 & 56,00 \\
\hline 2.2. Pintura de artes/placas & 4 & 16 & 16 & 0 & 0 & 16 & 9,6 \\
\hline 2.3 Pinturas de artes/tecidos & 1 & 16 & 0 & 8 & 0 & 0 & 4,8 \\
\hline 3. Montagem e Acabamento & 28 & 648 & 872 & 568 & 912 & 760 & 752 \\
\hline 3.1 Costura & 8 & 200 & 200 & 120 & 240 & 200 & 192 \\
\hline 3.2 Montagem/Adereço & 20 & 448 & 672 & 448 & 672 & 560 & 560 \\
\hline 4. Embalagem e Organixação & 3 & 8 & 8 & 8 & 8 & 8 & 8 \\
\hline 4.1 Embalagem & 3 & 8 & 8 & 8 & 8 & 8 & 8 \\
\hline Total HH & & 878 & 1118 & 782 & 1078 & 1022 & - \\
\hline
\end{tabular}

Fonte: Autoria própria

Para identificação dos gargalos analisou-se o percentual de influência de hora-homem (HH) de cada setor no tempo total de produção de cada fantasia (dividindo-se a quantidade de $\mathrm{HH}$ de cada setor pelo total de $\mathrm{HH}$ demandada para produção de cada fantasia).

Os resultados associados a essa análise encontram-se na Tabela 2 e na Figura 5.

Tabela 2. Tempo total de produção das fantasias $(\mathrm{HH})$

\begin{tabular}{|c|c|c|c|c|c|c|}
\hline \multirow{3}{*}{$\begin{array}{c}\text { Tempo total de produçäo das } \\
\text { fantesias }(\mathrm{HH})\end{array}$} & Fl & $F 2$ & F3 & F4 & F5 & \multirow{2}{*}{$\begin{array}{l}\text { Total } \\
4878\end{array}$} \\
\hline & 878 & 1118 & 782 & 1078 & 1022 & \\
\hline & \multicolumn{5}{|c|}{$\%$ de influência no processo } & Média \\
\hline 1. Pré-produção & $15,26 \%$ & $14,85 \%$ & $18,16 \%$ & $9,46 \%$ & $17,81 \%$ & $15,11 \%$ \\
\hline 2. Corte e Pintura & $10,02 \%$ & $6,44 \%$ & $8,18 \%$ & $5,19 \%$ & $7,05 \%$ & $7,38 \%$ \\
\hline 3. Montagem e Acabamento & $73,80 \%$ & $78,00 \%$ & $72,63 \%$ & $84,60 \%$ & $74,36 \%$ & $76,68 \%$ \\
\hline 4. Embalagem e Organização & $0,91 \%$ & $0,72 \%$ & $1,02 \%$ & $0,74 \%$ & $0,78 \%$ & $0,83 \%$ \\
\hline
\end{tabular}

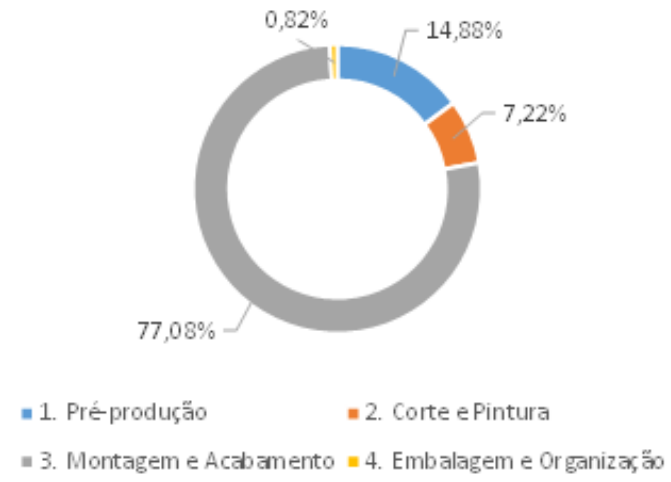

Figura 5. Percentual de influência no total de HH para produção de todas as fantasias Fonte: Autoria própria 
Nota-se, que o setor que consome maior tempo durante todo o processo de fabricação de fantasias é o de Montagem e Acabamento, consumindo mais de $75 \%$ do tempo total do processo produtivo, comprovando que este setor representa o gargalo do processo.

Diante do exposto, o foco de análise do presente estudo foi identificar as possibilidades de implementação de melhorias no setor de Montagem e Acabamento. Para isso, foi analisado um conjunto de possibilidades para reduzir os desperdícios (de tempo e materiais) durante todo o processo.

\section{MODELO CONCEITUAL}

Na etapa da modelagem conceitual, o modelo abstrato que está na mente do analista deve ser apresentado de acordo com alguma técnica de representação, a fim de torná-lo mais fiel à realidade, de modo que outras pessoas possam entendê-lo (LIMA et al., 2011). Para a construção do modelo conceitual, utilizou-se a técnica de modelagem IDEF-SIM (Integrated Definition Methods - Simulation), com figuras e formas do programa Power Point para construir o diagrama.

De acordo com Montevechi et al. (2010) a técnica pode ser utilizada em dois momentos distintos do projeto de simulação. A primeira possibilidade é a utilização na fase de modelagem conceitual, onde o modelador registra o sistema a ser simulado. Para o presente artigo, foi utilizada esta alternativa.

Além disso, esta técnica tem um aspecto visual de fácil modelagem e entendimento. (SÁ, 2011). Ainda segundo Montevechi et al. (2010), o grande benefício do uso do IDEFSIM nesta fase é a construção de um modelo conceitual com algumas características que permitirão uma redução do tempo gasto na fase de modelagem computacional. A Figura 6 apresenta o modelo conceitual do processo de fabricação de fantasias de ala.

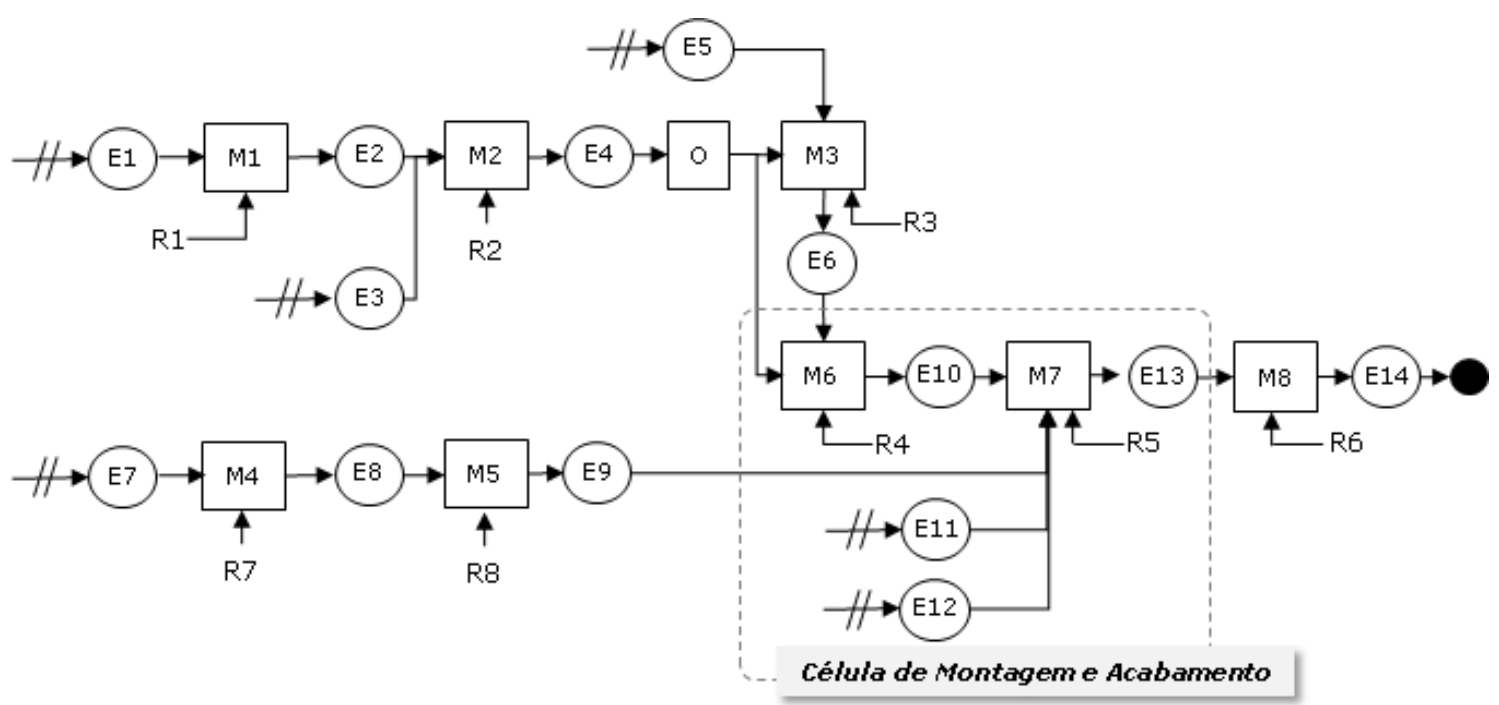

Figura 6. Modelo conceitual do processo de fabricação de fantasias de ala Fonte: Autoria própria

Para o diagrama IDEF-SIM elaborado existem quatorze entidades e nove funções. A Tabela 3 detalha abaixo a descrição das entidades e suas respectivas funções. 
Tabela 3. Descrição das entidades e funções

$\begin{array}{cl}\text { Entidades } & \text { Nome } \\ \text { E1 } & \text { Papelão } \\ \text { E2 } & \text { Moldes elaborados } \\ \text { E3 } & \text { Tecidos } \\ \text { E4 } & \text { Tecidos cortados } \\ \text { E5 } & \text { Tinta para tecido } \\ \text { E6 } & \text { Tecidos pintados } \\ \text { E7 } & \text { Materiais para placas (acetato, borracha EVA) } \\ \text { E8 } & \text { Placas produzidas } \\ \text { E9 } & \text { Placas/artes pintadas } \\ \text { E10 } & \text { Tecidos costurados } \\ \text { E11 } & \text { Estruturas de arame } \\ \text { E12 } & \text { Adereços e acabamentos } \\ \text { E13 } & \text { Fantasia montada (E6+E9+E10+E11+E12) } \\ \text { E14 } & \text { Fantasia embalada }\end{array}$

$\begin{array}{cl}\text { Funçöes } & \text { Nome } \\ \text { M1 } & \text { Modelagem } \\ \text { M2 } & \text { Enfesto e Corte } \\ \text { M3 } & \text { Pintura de artes/tecido } \\ \text { M4 } & \text { Produção de placas } \\ \text { M5 } & \text { Pintura de artes/placa } \\ \text { M6 } & \text { Costura } \\ \text { M7 } & \text { Montagem/Adereços } \\ \text { M8 } & \text { Enbalagem }\end{array}$

Fonte: Autoria própria

Conforme apresentado na Figura 6, a produção de fantasias inicia-se paralelamente nas etapas de Modelagem (M1); onde 3 operadores (R1) fabricam os moldes de cada peça utilizando papelão (E1); e Produção de placas (M4), com moldes característicos de cada fantasia utilizando acetato ou borracha EVA (E7), por 2 operadores (R7).

Em seguida, 6 operadores (R2) colocam os moldes elaborados (E2) em cima dos tecidos (E3) para o corte dos mesmos na etapa de Enfesto e Corte (M2). Em paralelo, as placas produzidas (E8) são pintadas (M5) por 4 operadores (R8), resultando em placas/artes pintadas (E9).

Após a etapa de Enfesto e Corte, os tecidos cortados (E4) podem seguir dois caminhos: seguem para a etapa de pintura (M3), onde 1 operador (R3) utiliza tintas (E5) para pintá-los ou vão para a etapa de costura (M6), realizada por 8 operadores (R4).

Em algumas fantasias os tecidos cortados (E4) não precisam ser pintados e vão diretamente pra etapa de costura (M6), resultando nos tecidos costurados (E10).

Na etapa de Montagem/Adereço (M7), aos tecidos costurados (E10) são adicionados às placas/artes pintadas (E9), às estruturas de arame (E11) e aos adereços e acabamentos (E12). É a etapa onde são utilizados mais operadores (R5), sendo 20 no total.

Após esta etapa a fantasia já está montada (E13) e é embalada (M8) por 3 operadores (R6). O produto final é a fantasia embalada (E14) e pronta para ser transportada para o desfile.

\section{MODELO COMPUTACIONAL}

A partir do problema apresentado e dos dados coletados, detectou-se como gargalo principal, o setor de Montagem e Acabamento. Assim, foi utilizada a técnica de modelagem e simulação para testar diferentes possibilidades de organização do processo produtivo.

O modelo computacional estruturado buscou simular uma linha de produção por lotes de fantasias devido a necessidade de otimizar o tempo de produção e eliminar o gargalo principal.

O modelo atual de produção é funcional e realiza a produção em "ateliês" que são organizados por células (compostas de costureiros e aderecistas), onde cada célula é responsável pela montagem e acabamento do início ao fim de determinadas fantasias. Devido à ausência de métodos padronizados e empirismo neste processo, estima-se que esta etapa de montagem e acabamento demande um tempo significativo.

Para o presente trabalho, foram construídos dois modelos computacionais no software de modelagem e simulação FlexSim. Para fins da modelagem, optou-se por programar a produção iniciando daquelas fantasias que demandam maior quantidade de horas, conforme os dados da Tabela 1. Ou seja, a sequência de produção considerada foi: Modelo F2 (1118 
horas), Modelo F4 (1078 horas), Modelo F5 (1022 horas), Modelo F1 (878 horas) e Modelo F3 (782 horas). As características e informações referentes aos modelos citados estão explicitados a seguir e apresentados nas Figuras 7 e 8.

Modelo 1 - Dados da simulação:

- Ordem de produção: 2, 4, 5, 1, 3.

- Número de replicações: 30

- Média do tempo total de produção (Run Time): 3.082,27 horas.

- Gargalos no processo produtivo: Costura e Montagem.

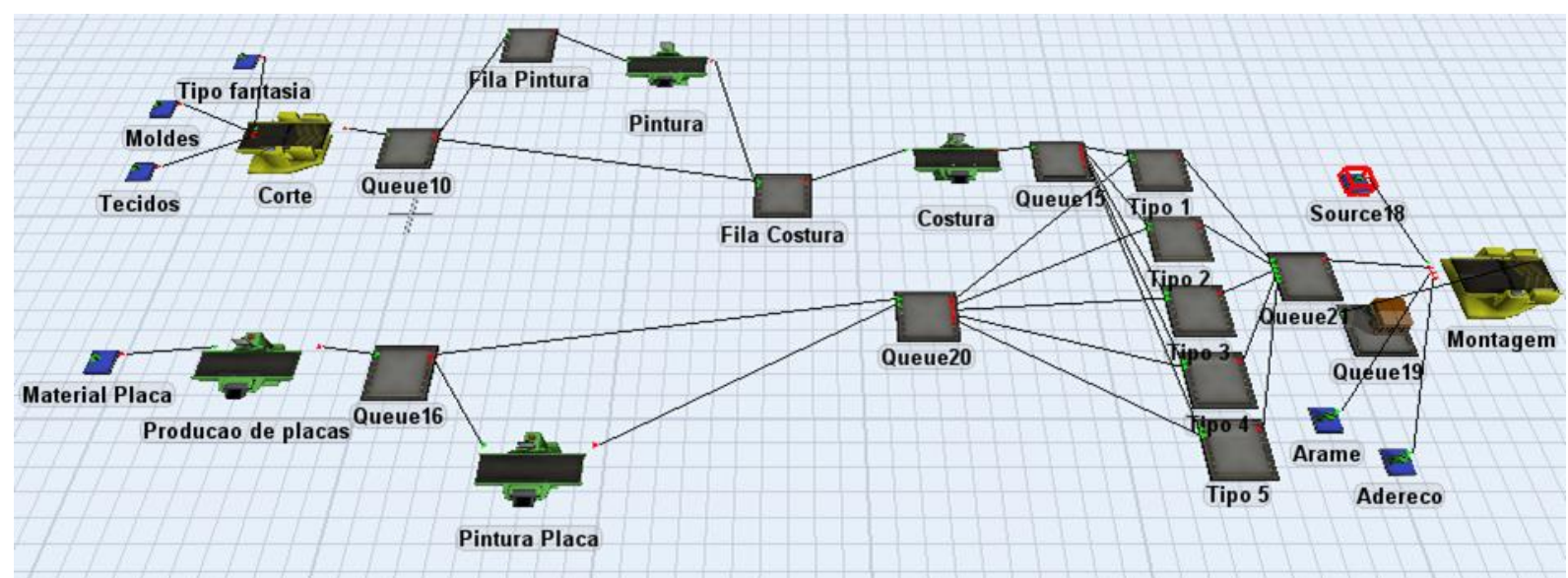

Figura 7. Modelo 1 - Simulação do processo atual (produção funcional por ateliê)

Fonte: FlexSim

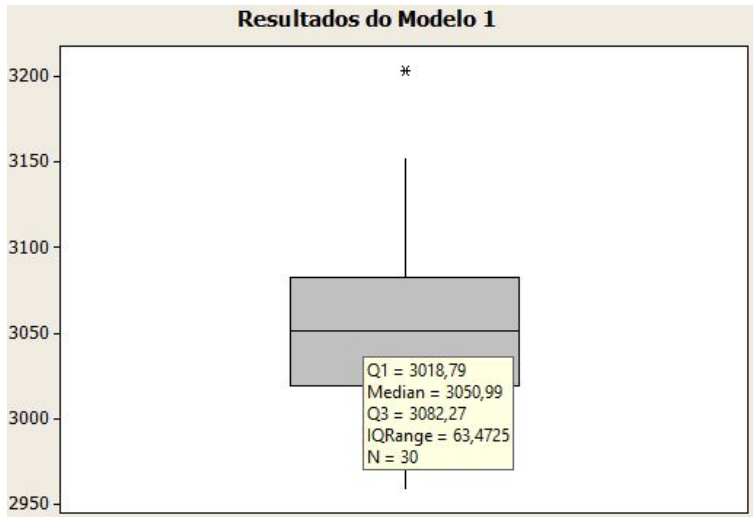

Figura 8. Modelo 1 - Modelo computacional elaborado no FlexSim Fonte: FlexSim

O segundo modelo de simulação contempla o processo com implantação do sistema de produção por lotes, através da duplicação do setor de Costura e Montagem. As Figuras 9 e 10 ilustram os dados a seguir.

Modelo 2 - Dados da simulação:

- Ordem de produção: 2, 5, 4, 1, 3.

- Número de replicações: 30

- Média do tempo total de produção (Run Time): 1.721,78 horas 


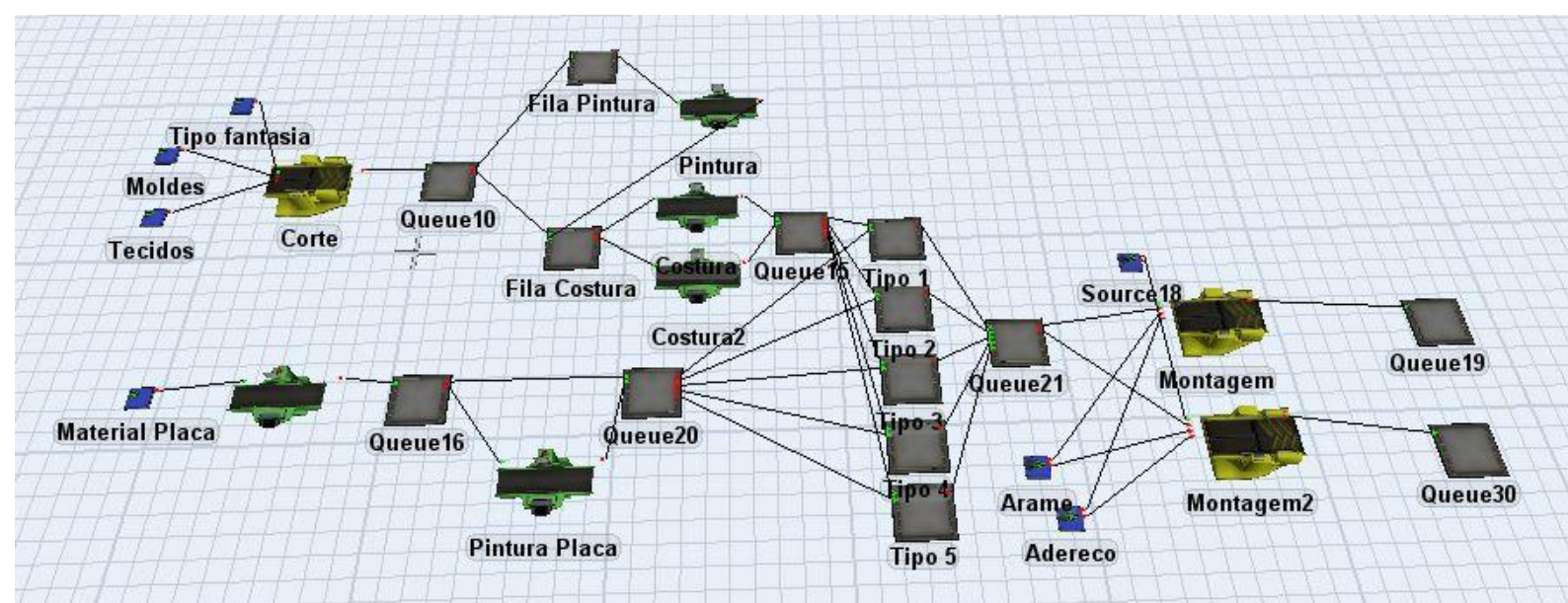

Figura 9. Modelo 2 - Simulação do processo com implantação do sistema de linha de produção por lotes (com duplicação da Costura e Montagem)

Fonte: FlexSim

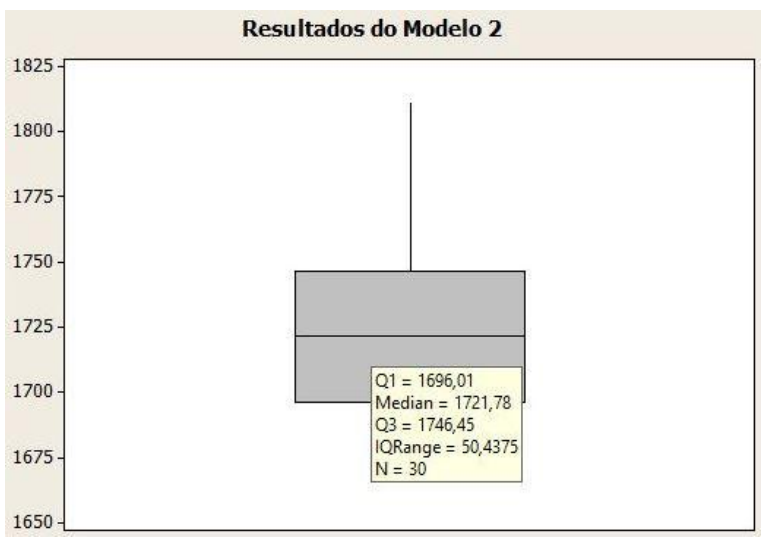

Figura 10. Modelo 2 - Modelo computacional elaborado no FlexSim

Fonte: FlexSim

Através dos modelos computacionais construídos e das simulações realizadas, foi possível notar uma redução significativa no tempo total do processo (que corresponde ao Run Time). Inicialmente, conforme já fora apresentado, o tempo total do processo para a produção de todos os lotes de fantasia era de 3.082,27 horas.

Após análise aprofundada dos resultados da simulação do Modelo 1, notou-se que havia muita espera para se iniciar os processos de Costura e Montagem. Isso posto, para fins de apreciação, incrementou-se o Modelo 2 com mais uma célula de Costura e Montagem objetivando reduzir o tempo ocioso. Como já era esperado na teoria, houve uma redução de 3.082,27 horas para um tempo total médio de 1.721,78 horas, representando uma diminuição de $44,14 \%$.

\section{CONCLUSÕES}

A partir dos resultados obtidos através da realização da modelagem e simulação dos modelos computacionais 1 (atual) e 2 (proposto) e considerando que o objetivo central do presente estudo era a análise das etapas do sistema de produção de fantasias, a identificação dos potenciais gargalos e a proposição de melhorias no sistema produtivo, entende-se que o objetivo do presente estudo foi alcançado.

Inicialmente, valendo-se das técnicas de modelagem e simulação, buscou-se analisar como o modelo atual de produção se comporta utilizando o software FlexSim.

A partir disso, foi possível notar que o tempo total de produção dos lotes de fantasia no Modelo 1 era consideravelmente elevado (3.082,27 horas). No modelo 2, como sugestão de melhoria no processo produtivo de fantasias, foi proposta uma otimização no sistema de 
produção baseado na duplicação do setor de Costura e Montagem. O sistema, anteriormente funcional (Modelo 1), com os ateliês produzindo separadamente determinados modelos de fantasia, foi alterado para uma linha de produção por lotes de fabricação (Modelo 2).

Através dos resultados do Modelo 2, foi possível perceber uma redução de 44,14\% do tempo total do processo produtivo dos lotes das fantasias analisadas em comparação com o sistema atual de produção.

Desse modo, conclui-se que o emprego da simulação é extremamente útil para o estudo de processos produtivos, trazendo embasamento para possíveis modificações nos processos, e ainda conhecer os benefícios alcançados antes de realizar um investimento nas mudanças propostas ou efetuar qualquer alteração na planta de produção.

É importante ressaltar que o fator custo não está sendo considerado como fim de análise desse estudo, sendo apenas o fator tempo, relevante nesse momento. No entanto, para que as propostas de melhorias sejam abordadas com mais profundidade, seria necessário fazer uma análise que contemple os custos de produção envolvidos, podendo ser estudados posteriormente como desdobramento para futuros trabalhos.

\section{REFERÊNCIAS BIBLIOGRÁFICAS}

[1] CHWIF, L.; MEDINA, A. Modelagem e Simulação de Eventos Discretos: Teoria e Aplicações. 3 ed. São Paulo: Ed. Bravarte, 2010.

[2] GIL, Antonio Carlos. Como elaborar projetos de pesquisa. São Paulo, v. 5, 2002.

[3] G. R. E. S Acadêmicos do Grande Rio. Disponível em: <http://www.academicosdogranderio.com.br>. Acesso em: 1 de maio de 2014.

[4] INGALLS, Ricki G. Introduction to simulation. In: Proceedings of the 40th Conference on Winter Simulation. Winter Simulation Conference, 2008. p. 17-26.

[5] LEAL, et al. Uma Proposta de Técnica de Modelagem Conceitual para a Simulação através de Elementos do IDEF. 40 Simpósio Brasileiro de Pesquisa Operacional, 2008.

[6] LIESA, Liga Independente das Escolas de Samba do Grupo Especial do Rio de Janeiro. Regulamento específico dos desfiles das escolas de samba do grupo especial da LIESA: Carnaval 2014. Disponível em: http://liesa.globo.com/2015/material/carnaval14/regulamento/Regulamento\%20Carnava 1\%202014\%20-\%20LIVRO\%20-\%20miolo.pdf. Acesso em: 29 de abril de 2014.

[7] LIMA, Josiane Palma; LOBATO, Kelly Carla Dias; LEAL, Fabiano. Aplicação do IDEF-SIM na modelagem conceitual de processos de seleção de resíduos sólidos urbanos. XLIII Simpósio Brasileiro de pesquisa Operacional, Ubatuba, p. 2904-2913, 2011.

[8] MONTEVECHI, J. A. B.; LEAL, F.; PINHO, A. F.; COSTA, R. F. S.; OLIVEIRA, M. L. M.; SILVA, A. L. F. Conceptual modeling in simulation projects by mean adapted IDEF: an application in a Brazilian tech company. In: Winter Simulation Conference, Proceedings... Baltimore, MD, USA, 2010.

[9] RIBEIRO, Josir David; DEZORDI, Vitchenzo Zimmer; DE OLIVEIRA, Alexandre Silva. Modelagem e Simulação - Aplicação a uma linha de manufatura de componentes Automotivos. Anais do Salão Internacional de Ensino, Pesquisa e Extensão, v. 3, n. 2, 2011.

[10] SÁ, A. et al. Simulação computacional para produção de pasta diamantada. Revista científica Exatas \& Engenharia, v. 1, n. 01, 2011. 
[11] VERGARA, Sylvia Constant. Projetos e relatórios de pesquisa em administração. 13 ed. São Paulo: Atlas, 2011.

[12] ZHU, X. et al. A Flexsim-based Optimization for the Operation Process of Cold-Chain Logistics Distribution Centre. Journal of Applied Research and Technology, v. 12, n. 2, 2014. 